\title{
AC 2009-1215: ASSESSMENT OF THE VANTH ENGINEERING RESEARCH CENTER ON GRADUATE STUDENTS
}

James Cawthorne, Purdue University

Osman Cekic, Purdue University

Monica Cox, Purdue University

Melissa Stacer, Purdue University 


\title{
Assessment of the VaNTH Engineering Research Center Experience on Graduate Students
}

\begin{abstract}
The Vanderbilt-Northwestern-Texas-Harvard/MIT (VaNTH) Engineering Research Center, started in 1999, has focused on improving bioengineering education through the applications of learning science, learning technology, and assessment and evaluation within the domain of bioengineering. The work led to the development of novel approaches to instruction based upon the "How People Learn" (HPL) framework using the technology of the STAR Legacy Cycle. Graduate students worked with faculty within VaNTH to use the "How People Learn" framework elements to develop teaching modules that produced greater learning with understanding about bioengineering than traditional strategies.
\end{abstract}

This paper discusses results of the exploratory quantitative survey on the impact of the VaNTH experience on participating graduate students. The results evaluate whether participants' familiarity with the HPL framework changes with participation in the VaNTH ERC.

Furthermore, self-reports about their participation in the VaNTH ERC provides insight into what graduate students identified as take away lessons for their careers. Finally, sharing their views on the concept of effective instruction generate demonstrates whether thinking about learning and teaching impacts their understanding of the process. This paper will equally focus on how to tie the results of the exploratory study to the emergent explanatory protocol designed to understand more fully the experience of graduate student participants while working with the VaNTH ERC.

\section{Introduction}

The National Science Foundation's Engineering Research Center (ERC) program was created in 1984 to encourage collaborations between industry and academia. Since their creation, these multi-university, multidisciplinary ERCs have increased the engineering community's understanding of specific challenges within engineering and engineering education have impacted positively the experiences of undergraduate and graduate students engaged in ERC activities $^{1}$. More specifically, ERCs provide opportunities for students to conduct cutting-edge research; to disseminate their findings in disciplinary, education, and industrial communities; and to interact closely with faculty, students, and industry members with vested interests in the ERC.

The Vanderbilt-Northwestern-Texas-Harvard/MIT (VaNTH) Engineering Research Center for Bioengineering Educational Technologies was founded in 1999 with a mission of improving the field of bioengineering via the development and dissemination of educational materials based upon the four tenets of the "How People Learn" (HPL) framework ${ }^{2}$. Comprised of researchers representing the domains of bioengineering, learning science, learning technology, and assessment and evaluation, this ERC explored the development of VaNTH innovations ${ }^{3-8}$ along with the effects of VaNTH upon students ${ }^{9}$. This current study extends previous research by examining the impact of the VaNTH experience on a sample of graduate students who participated in VaNTH. The results evaluate whether participants' familiarity with the HPL 
framework changes with participation in the VaNTH ERC. Furthermore, self-reports about their participation in the VaNTH ERC provides insight into what graduate students identified as take away lessons for their careers.

\section{Research Methodology}

The study of the impact of VaNTH ERC participation on professional development for graduate students in biomedical engineering is a two part exploratory-explanatory study ${ }^{10}$. For the purposes of this study, professional development was defined as learning the HPL framework and utilizing the framework within their professional endeavors - research, teaching, and community development. The research reported in this paper refers only to the exploratory survey responses obtained from former VaNTH graduate students about their experiences with tenets of the HPL framework.

Population

This study targeted the graduate student participants in the VaNTH ERC between 1999 and 2007. Graduate students played a critical role in all research endeavors - development, implementation, and assessment of educational innovations. In the case of the VaNTH ERC, graduate students contributed to the research and teaching efforts by developing and by implementing the HPL framework within biomedical engineering modules. Of the twenty-nine respondents in this study, the majority $(59 \%)$ were recruited by colleagues already participating in $\mathrm{VaNTH}$, while another $38 \%$ were engaged via institutional efforts. At the time of the study, approximately one third of the respondents were still graduate students, $14 \%$ were post doctoral fellows/researchers, 35\% held teaching potions at higher education institutions (associate professor), and $21 \%$ were working in other areas, possibly out of the academe. The distribution of the participants by gender was about fifty-fifty. Sixty-six percent of respondents were white, $10 \%$ were Asian, and 14\% were African-American. Ninety percent of the respondents were US citizens and permanent residents compared to $10 \%$ non-US citizens.

\section{Survey Construction}

The exploratory survey developed for the graduate students sought to glean insights from respondents about their experiences with HPL-oriented, or challenge-based instruction before, during, and after their participation in VaNTH. Participants were asked to (1) reflect and recall their understanding of the HPL framework and their concept of effective teaching, (2) describe their experiences while participating in $\mathrm{VaNTH}$, and (3) identify how their participation in VaNTH, in particular their exposure to HPL and the STAR Legacy Cycle, influence their current career work.

The survey consisted of eighteen Likert scale, or multiple selection, quantitative questions, three of which were demographic oriented, and six open-ended qualitative questions. The questions were developed and refined through iteration and collaboration by the research team to meet the identified goals of this assessment research. The questions were divided into four categories: (1) pre-VaNTH experience, (2) VaNTH experience, (3) post-VaNTH experience, and (4) demographics. The survey then was piloted by members of a research team that was highly involved within the VaNTH ERC and who served as expert judges providing 
content validity to the survey. Finally, the survey was converted to an on-line format and prepared for disbursement to previously identified graduate students.

\section{Data Collection}

Each graduate student was e-mailed a link to the survey and a unique activation code that was tied to their name. Participants could access the on-line survey, which was preceded with a consent form approved by Purdue University's Institutional Review Board (IRB). The IRB will allow researchers to correlate each participant's response to their name in order to allow researchers to identify interviewees for the explanatory phase of the research study and to provide insight into possible protocol questions. At the completion of allotted time for survey completion, collected participants' responses were converted to an Excel spreadsheet in preparation for data analysis.

\section{Data Analysis}

The survey produced both quantitative and qualitative responses requiring analysis. The quantitative data were downloaded into an excel spreadsheet and adjusted for performing analysis using the statistical package, SPSS. The quantitative results of the web survey were analyzed using Chi-square testing to identify statistical significance and/or trends. Groupwise comparisons were useful in comparing the self-reported effect of the VaNTH ERC, in particular the HPL framework, on graduate student professional development. In performing some of the groupwise comparison analysis, Likert responses (i.e. seldom/frequently/always or high/medium/low impact) were combined to create stronger associations for identifying general trends within the data.

Qualitative responses were coded and interpreted using open coding. The process for coding, identifying, and making assertions from the qualitative data began with several initial readings of the data to become immersed in participants' responses. After several passes, the data were parsed using key words that captured the essence of participants' respondents in the mind of researchers. The unit of analysis in this study was the entire response provided, as opposed to single key words or phrases, since it best represented the ideas of the participants. The words, or phrases, identified by the researcher were then grouped, if possible, into larger assemblages that incorporated several responses into a potential theme. The individual coded responses were tested for strength against the identified theme to determine if a strong assertion could be made using the coded data. Assertions are reported in this paper based upon how participants envisioned the concept of effective teaching, pre- and post- their VaNTH ERC experience, and in regards to their larger takeaways from their participation ${ }^{11-13}$.

\section{Results and Discussion}

This section of the paper describes the quantitative and qualitative results of the study. The results reported are trends associated with graduate student participants' experiences with VaNTH. 
Quantitative analysis

Prior to their involvement with the VaNTH project, many of the participants identified that they were unfamiliar with education, research and learning strategies for engineering education. Only $34 \%$ of graduate student participants had been engaged in some form of education-oriented research. Nearly two-thirds of the participants had no extensive experience with implementing educational concepts into research for "understanding" of learning and/or design of biomedical educational modules. Figure 1 shows the HPL framework components most unfamiliar to participants prior to their involvement in VaNTH. Of the four lenses, the community-centered dimension was the least familiar followed by learner-, knowledge-, and assessment-centered, respectively.

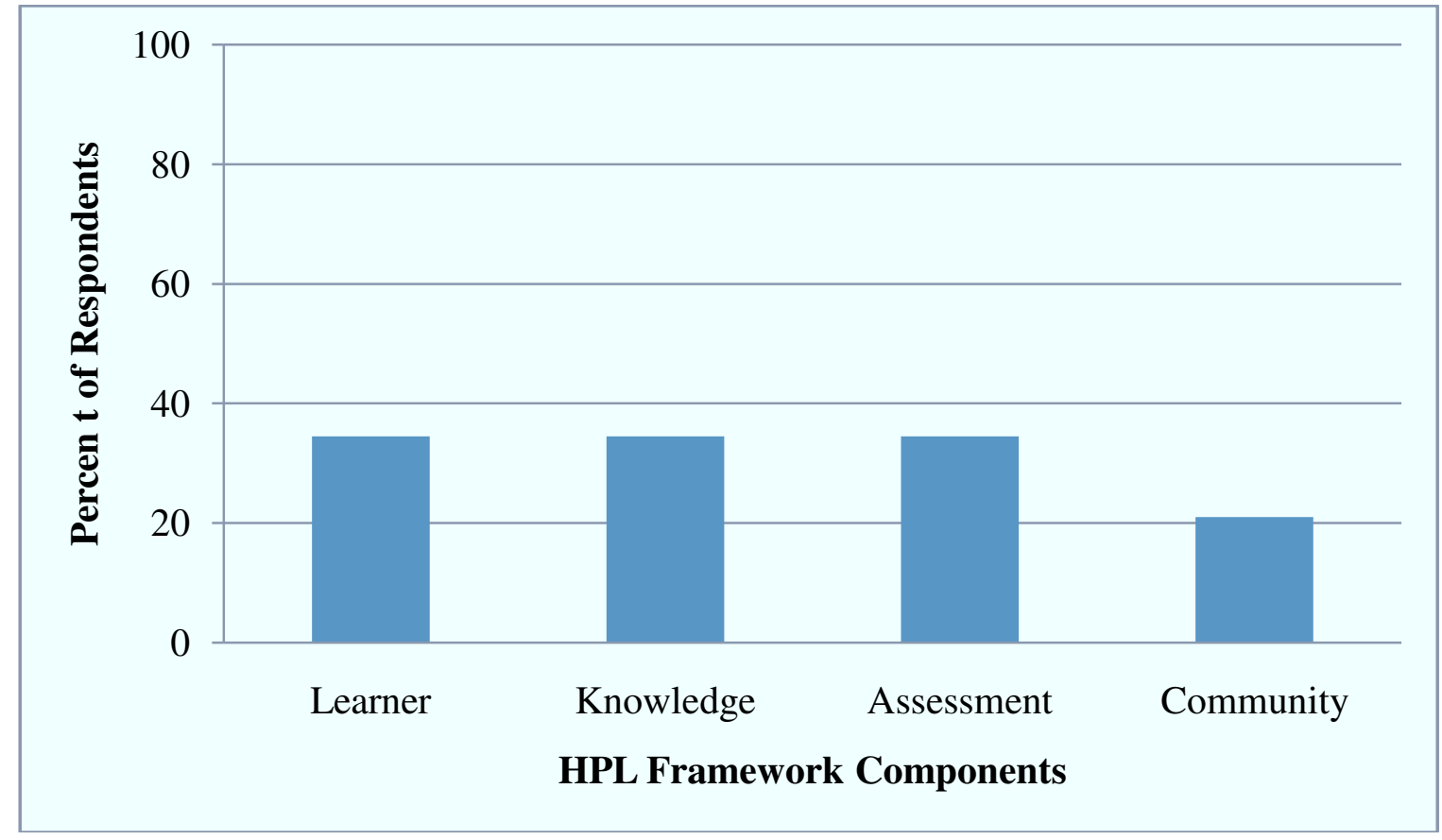

Figure 1: Graduate student respondents Pre-VaNTH familiarity with HPL framework (n=29).

In responding to their experiences of actively engaging a VaNTH project, graduate students made two strong claims that may have impacted their overall view of the process. First, the majority of graduate students $(73 \%)$ found implementing the HPL framework into their activities, research or teaching, to be somewhat of a challenge. Additionally, graduate students generally felt they were not being engaged actively in additional VaNTH activities (i.e. meetings, seminars, etc.) at their institutions. These responses indicate a possible personal experience for graduate students of not being engaged authentically in their VaNTH projects. The lack of engagement may have impacted the student's view of their work in the VaNTH ERC and their perspectives of the usefulness of the HPL framework components as an approach to learning.

Graduate student participants clearly indicate that their participation in the VaNTH ERC has had some meaningful impact on their professional activities. Figure 2 illustrates how much respondents continue to use the various HPL components during their current professional 
activities. Respondents reported using the knowledge-centered dimensions most. Comparing Figures 1 and 2, community-centered perspective has become an important contributor to graduate students' ongoing professional activities despite how few incoming participants were familiar with the perspective. This could be attributed to exposure through their VaNTH experience about the ability to engage in work that brings together an entire community as a learning environment.

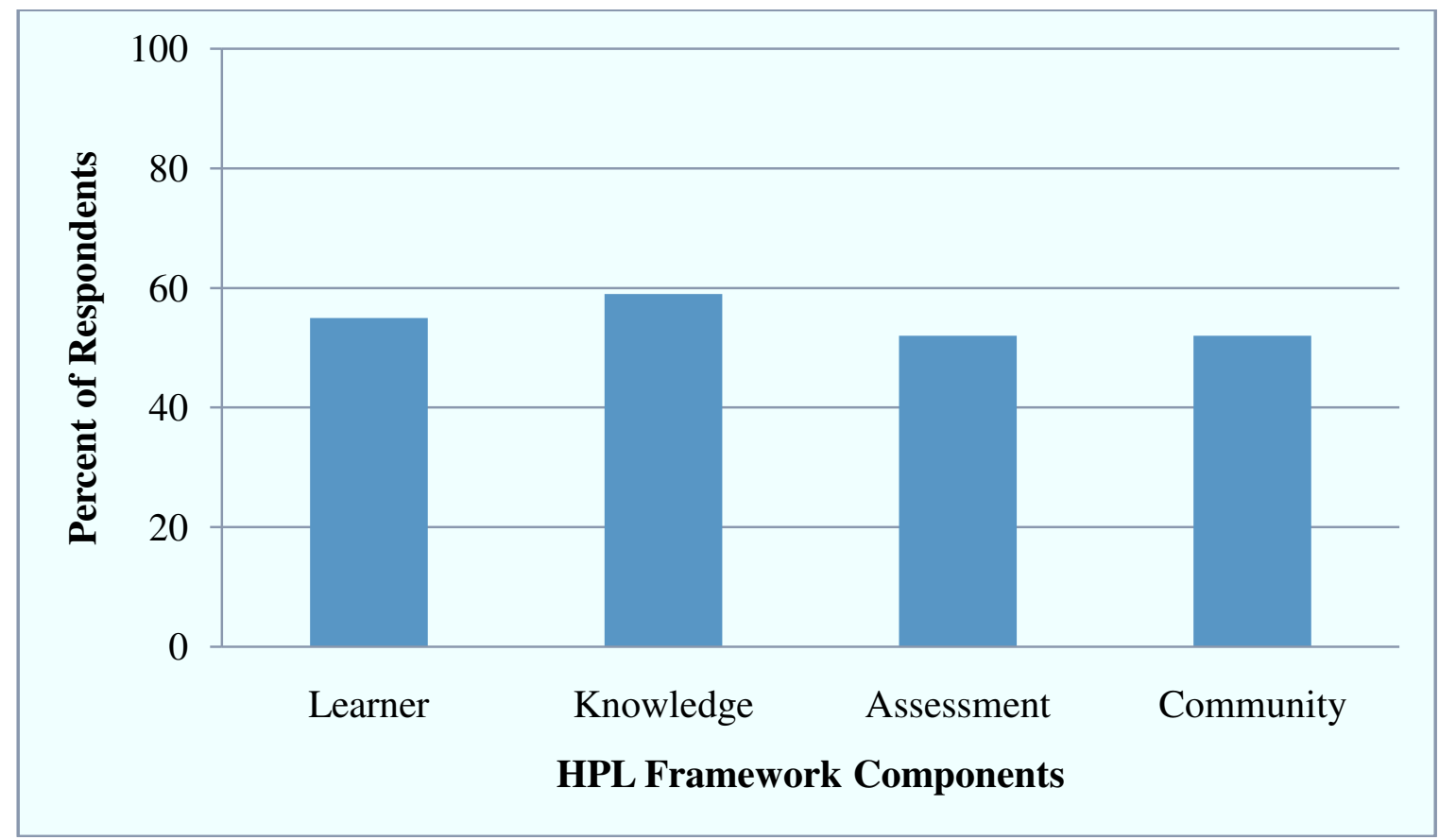

Figure 2: Graduate student respondents continuing to use HPL frame work components in their current professional activities $(n=29)$.

The VaNTH experience on professional activities after participating in VaNTH extends beyond the use of the HPL framework in participants' research, teaching, and service activities to also include general professional activities, such as networking. Figure 3 supports the view that participation in the VaNTH ERC is viewed by participants to have generally impacted professional development in these areas identified within the survey. The high impact in teaching correlates to the HPL framework components providing vocabulary, in the form of words and definitions, to concepts graduate students already had prior to participating in VaNTH.

The HPL framework is designed to breakdown the education process into components of learning. It is not surprising that participants would identify a heightened recognition of HPL framework components in their teaching activities. The slight significance of impact on research interests aligns with the notion that while many graduate students engaged in a VaNTH project with educational components as part of their graduate school experiences, most likely for funding. Individuals' actual research interests may be more aligned with technical research that does not allow for, or require, an educational component. 
The fact respondents identified their participation having a significant impact on their career choices, interactions with students (outside classroom), and interactions with colleagues indicates a certain social component existed through participant's involvement within the VaNTH ERC. This involvement could have been primarily within their home institution or on a larger national scale depending upon their project. This is supported by the fact that four in five respondents would recommend participation in the VaNTH ERC to one of their colleagues.

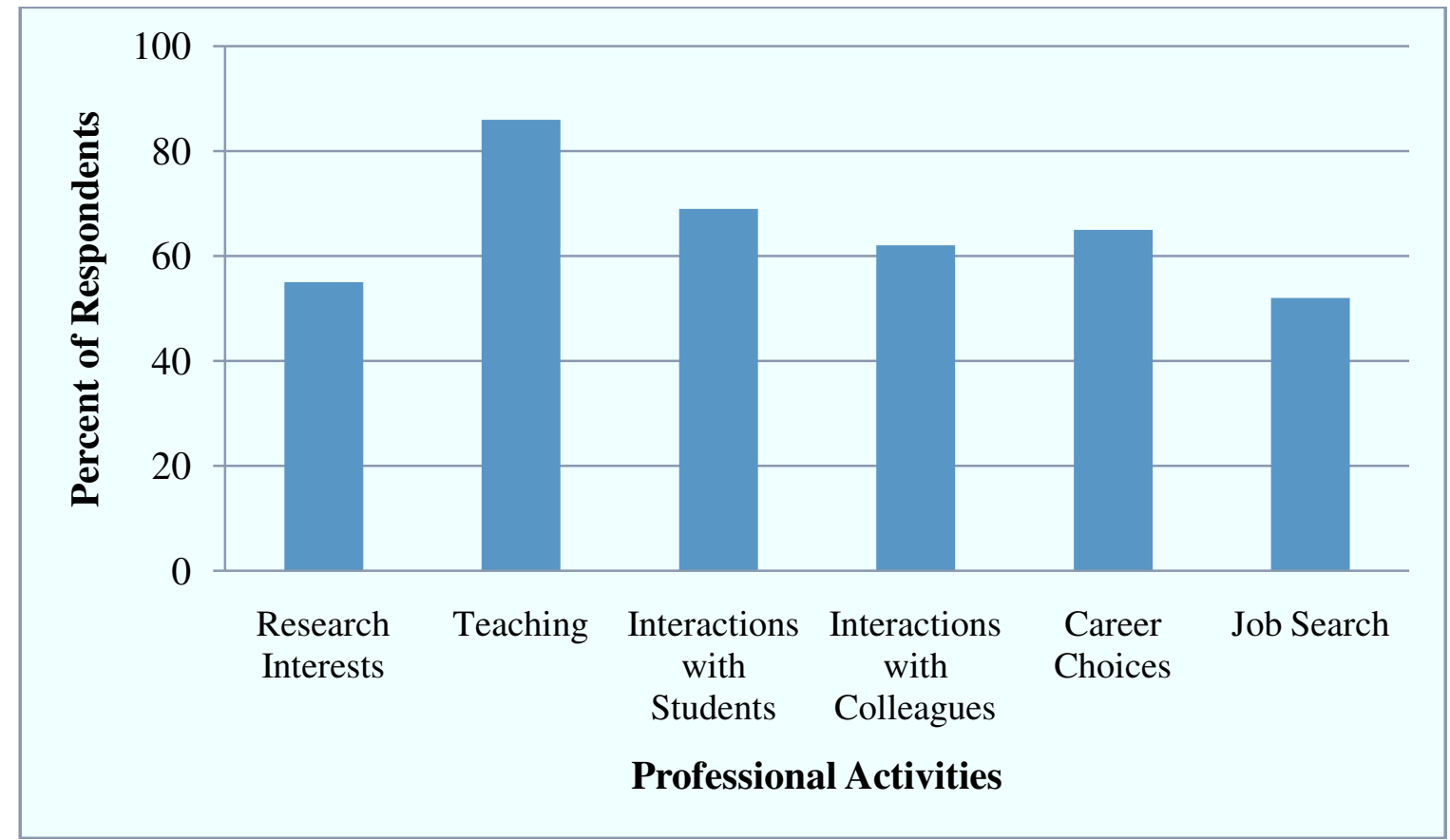

Figure 3: Graduate student respondents continuing to use HPL frame work components in their current professional activities $(\mathrm{n}=29)$.

Qualitative Analysis

Qualitative analysis of the open-ended questions on the survey tried to recognize a baseline experience for graduate student participants. It is clear, however, that no two experiences within this program were the same for graduate students most likely due to the variety of activities students engaged while in VaNTH and their length of time participating in the program.

Graduate students, despite participating in the VaNTH ERC through a variety of activities, clearly demarked themselves into one of two active roles within the VaNTH ERCresearch and development or teaching activities. Research and development roles refer to participants who primarily studied and refined the HPL and Star Legacy Cycle. This can involve creation of modules, as well as assessment of how HPL components work. Teaching roles centered on the act of engaging others in the learning process by applying HPL principles to the instruction regardless of level of class. This could be through teaching undergraduates or engaging in volunteer outreach activities. 
Graduate students identified a student-oriented approach to the concept of teaching in their pre-VaNTH recollections. Student-oriented teaching is defined here as the concept of teaching where the focus centers on the student learning the material through sufficient exposure, as identified by the participant, but not necessarily worried about the method of how the student is engaged to learn the material. Some examples of participants' responses about the concept of effective learning are:

"I would describe it as giving students the opportunity to learn."

"I would have described effective instruction as that which results in a measurable increase in the knowledge content of students and also facilitates problem solving."

This can be strewn as coming from a typical approach to education, where individuals ascribe their success in learning to their own ability to learn and expect others to be able to learn from simple exposure to concepts and ideas, as opposed to the role learning environments' play in influencing student learning processes.

When comparing pre- and post- VaNTH concepts of effective teaching, participants mostly identified no changes in their understandings of teaching effectiveness, or a reiteration of their previous concept of teaching effectiveness while adding in a mention of HPL and its components.

"It has not changed extensively, except that I have been exposed to the ideas of different learning styles."

"By this point in my education I think most people have formed their own way to learn - which is usually highly individualized. I think trying to force people into a certain framework is counter-productive."

"My concept still stands, but emphasizes the importance of selecting the right teaching and testing methods in order to learn properly. Hands-on and open ended questions sometimes work, but not always."

These responses raise questions about the role amount of time participating in the VaNTH ERC, since over half of the participants were active for less than two years. Furthermore, there are questions relating the quality of participants' role and their level of training and exposure to HPL components which may relate to the lack of significant expressions about HPL in their postVaNTH constructs of effective teaching.

\section{Development of Questions for Explanatory Study}

Many times participants in various projects acquire new vocabulary and assimilate into their work, but there is sometimes a question about accuracy in "understanding" the program's use of the concepts and the way individuals implement the new knowledge into their own schemas. 
Based upon the findings within this study, questions raised for explanatory study (i.e. the stories associated with VaNTH's impact) include the following:

- How did VaNTH participation impact professional development opportunities?

- What are some examples of the impact of HPL framework activities on respondents' teaching during their post-VaNTH activities?

- What do graduate student respondents know about the HPL framework components?

\section{Limitations}

There are some limitations associated with the results of this survey. The primary is the reliance on participant's self-reporting on their experiences. There is always a certain ambiguity associated with how individual respondents give value, and subsequently how they rate, a given experience. This issue is further exacerbated by the need of respondents to remember information that may have occurred years ago in responding to their pre-VaNTH and VaNTH experiences. Another limitation is that the response rate of approximately $25 \%$ provided such a small sample size that it is inappropriate to report statistical significance, but rather the reporting of statistical trends is most appropriate. Finally, there were no control and experimental groups identified for testing within this exploratory study.

\section{Conclusion}

The VaNTH ERC was initiated to design and implement a transformative, educational course of action in biomedical engineering. While much of this burden rested with faculty, administrators, and consultants in the biomedical engineering and learning sciences disciplines, graduate students, through funding and participation opportunities, had a chance to contribute to the project and to gain some experience - technically and professionally. This survey, although exploratory in nature, provided a suggestion about what influence the VaNTH ERC had on the professional development graduate student participants.

There are three general conclusions that can be stated regarding graduate students' professional development through their participation in the VaNTH ERC. First, graduate students believed their participation in the VaNTH ERC is impacting aspects of their professional activities today. This is particularly evident in how they reference the continued use of HPL components in relation to teaching. Furthermore, graduate students' concepts of effective teaching did not seem to evolve extensively through participation in VaNTH. Their selfidentified views about the concept of effective teaching have not changed while participating in VaNTH, except introducing some HPL vocabulary. Finally, participation in any research activity may impact current and future professional opportunities. In particular, their teaching and networking skills (i.e. interaction with colleagues and students outside the classroom) were influenced. 


\section{Bibliography}

1. Ailes, C., Feller, I., \& Coward, H. (2006). THE IMPACT OF ENGINEERING RESEARCH CENTERS ON INSTITUTIONAL AND CULTURAL CHANGE IN PARTICIPATING UNIVERSITIES: Arlington VA: SRI International. Available at http://www.sri.com/policy/csted/reports/sandt/documents/ERCCulturalImpact.pdf, Last accessed on February 1, 2009.

2. Bransford, J., Brown, A., \& Cocking, R. (2000). How people learn: National Academy Press Washington, DC.

3. Birol, G., Liu, S. Q., Smith, H. D., \& Hirsch, P. (2006). Educational Modules in Tissue Engineering Based on the "How People Learn" Framework. BEE-j, 7.

4. Birol, G., McKenna, A. F., Smith, H. D., Giorgio, T. D., \& Brophy, S. P. (2002). Integration of the "How People Learn" Framework into Educational Module Development and Implementation in Biotechnology. Second Joint EMBS/BMES Conference (pp. 2640-2641). Houston: IEEE.

5. Barr, R, Pandy, M, Petrosino, A, Austin, B and Goldberg, E. (2004). Classroom Testing of VaNTH Biomechanics Learning Modules. Proceedings of the American Society for Engineering Education Session 1109: 20 pages (2004).

6. Greenberg, J.E., Smith, N.T. and Newman, J.H. Instructional Module in Fourier Spectral Analysis, Based on Principles of "How People Learn”. Journal of Engineering Education 92: 155-165, 2003.

7. Cordray, D. S., Pion, G. M., Harris, A., \& Norris, P. (2003, July/August). The Value of the VaNTH Engineering Research Center. IEEE Engineering in Medicine and Biology Magazine , 47-54.

8. Cox, M. F., \& Cordray, D. S. (2008). Assessing Pedagogy in Bioengineering Classrooms: Quantifying Elements of the "How People Learn" Model Using the VaNTH Observation System (VOS). Journal of Engineering Education , 413-431.

9. Giorgio, T. D., Brophy, S. P., Birol, G., McKenna, A. F., \& Smith, H. D. (2002). Assessment of Educational Modules Based on the "How People Learn" Framework Delivered to Biotechnology Learners at Two Universities. Second Joint EMBS/BMES Conference (pp. 2642-2643). Houston: IEEEdfdd

10. Creswell, J. (2008). Educational Research: Planning, Conducting, and Evaluating Quantitative and Qualitative Research (Third ed.): Merrill Prentice Hall

11. Patton, M. (2002). Qualitative Research and Evaluation Methods: Sage Publications, Inc.

12. Lincoln, Y., \& Guba, E. (1985). Naturalistic Inquiry: Sage Publications Inc.

13. Auerbach, C., \& Silverstein, L. (2003). Qualitative Data: An Introduction to Coding and Analysis: New York University Press. 